\title{
High-normal alanine aminotransferase as a Predictor of significant liver histological injury in Chronic Hepatitis B Virus Infection with different HBV DNA levels
}

\author{
Ren shan \\ Beijing YouAn Hospital,Capital Medical Unviersity,China \\ Lu Junfeng \\ Beijing YouAn Hospital,Capital Medical Unviersity,China \\ Wang Kefei \\ Beijing YouAn Hospital,Capital Medical Unviersity,China \\ Ma Lina \\ Beijing YouAn Hospital,Capital Medical Unviersity,China \\ Zheng Yanhong \\ Beijing YouAn Hospital,Capital Medical Unviersity,China \\ Zheng Sujun \\ Beijing YouAn Hospital,Capital Medical Unviersity,China \\ Chen Xinyue ( $\nabla$ chenxydoc@163.com) \\ Beijing YouAn Hospital,Capital Medical Unviersity,China
}

\section{Research Article}

Keywords: Chronic hepatitis B (CHB), Liver biopsy, significant liver histological injury, Normal alanine aminotransferase (ALT), High-normal ALT, HBV DNA level

Posted Date: March 2nd, 2022

DOI: https://doi.org/10.21203/rs.3.rs-1361827/v2

License: (c) (i) This work is licensed under a Creative Commons Attribution 4.0 International License. Read Full License 


\section{Abstract \\ Objective}

We aimed to assess significant liver histological injury(SLHI) of chronic hepatitis B (CHB) patients with normal ALT in order to select clinical threshold of ALT.

\section{Methods}

We retrospectively examined 347 patients who underwent liver biopsy in Beijing You an hospital, Capital Medical University from January 2018 to January 2021. Univariate analysis of the clinical parameters versus inflammation and fibrosis was carried out.

\section{Results}

Of these 347 patients met the inclusion criteria, 174(50.1\%) patients had SLHI totally.The AUROC of the ALT associated with the diagnosis of SLHI was 0.572 for female and 0.6 for male with a cut-off value of $20 \mathrm{U} / \mathrm{L}$ and $25 \mathrm{U} / \mathrm{L}$, respectively $(p=0.04, p=0.013)$.Among HBeAg-positive patients, the proportion of SLHI in the high-normal ALT group (ALT > $20 \mathrm{U} / \mathrm{L}$ for female, $>25 \mathrm{U} / \mathrm{L}$ for male) with low HBV DNA loads $(<7$ log 10 $\mathrm{IU} / \mathrm{ml}$ )was higher(66.7\% vs 33.3\%, p<0.001); also the proportion in the HBeAg-negative with high-normal ALT and HBV DNA $\geqq 2000$ IU/ml was significantly higher(70\% vs $37.7 \%, p<0.001)$.

\section{Conclusion}

Clinical threshold of ALT to distinguish SLHI was 25U/L for male and 20U/L for female.The CHB patients with high-normal ALT and certain HBV DNA level ( $\geqq 2000 \mathrm{IU} / \mathrm{ml}$ for HBeAg-negative and < 7 log10 IU/ml for HBeAg-positive) were suggested to perform liver biopsy or noninvasive methods for histopathology assessment, then to be determined for antiviral therapy.

\section{Introduction}

Chronic hepatitis B virus (HBV) infection is a public health problem worldwide, and may cause a spectrum of diseases ranging from asymptomatic state to cirrhosis and hepatocellular carcinoma (HCC) ${ }^{[1]}$. Among chronic HBV infection patients, those with significant liver histological injury (SLHI) defined as inflammatory grade $\geqq G 2$ and/or fibrosis stage $\geqq$ S2 using the METAVIR scoring system are at increased risk for developing cirrhosis and HCC and should be considered for antiviral therapy immediately ${ }^{[2]}$. Liver biopsy is the gold standard for the diagnosis of SLHI ${ }^{[3]}$, but it examines only a very small part of the liver and there is a risk that this part might not be representative for the whole liver. Alanine transaminase (ALT) is the least costly and most widely used marker in chronic HBV infection patients ${ }^{[4]}$. Current guidelines on the management of chronic hepatitis $B(C H B)$ suggest that ALT more than upper limit of normal (ULN) should be one of the indications for antiviral therapy, and patients with normal ALT levels are considered to have "healthy" livers and may be suggested for regular follow-up rather than antiviral therapy immediately [2,5-6].

However, the definition of ULN for ALT in different laboratories and CHB guidelines is not consistent. Current ULN for ALT level were set, on average, at $40 \mathrm{U} / \mathrm{L}$ in studies conducted over the past 10 years ${ }^{[7-9]}$. Such threshold was adopted by EASL and APASL as a crucial criterion for determining treatment initiation for CHB. As for AASLD, the ULN of $35 \mathrm{U} / \mathrm{L}$ ALT for male and $25 \mathrm{U} / \mathrm{L}$ for female adults is recommended when guiding management decisions, which can improve disease outcome ${ }^{[5]}$. The selection of these cut off levels is based on the findings presented above in which patients with ALT levels above these cut-off values had a significantly higher rate of advanced fibrosis but below which minimal histologic adversity was observed ${ }^{[10-13]}$.

Compared with the threshold of ALT reduction in Europe and the United States, CHB guideline in China ${ }^{[6]}$ requires ALT level $>1 \times$ ULN as major determinant for indicating treatment initiation,which are based on ALT norms, expressed as a multiple of the ULN, defined by local laboratories; in other words, no absolute levels have been mentioned. In our clinical practice, normal ALT level was defined as $9 \sim 50 \mathrm{U} / \mathrm{L}$ for male, $7 \sim 40 \mathrm{U} / \mathrm{L}$ for women which was based on the industry standard issued by the Ministry of Health in $2013^{[14]}$. Obviously, unlike the range of normal ALT, clinical threshold of ALT is based on a special group infected with chronic HBV, where ALT levels represent significant inflammation and fibrosis of the liver and requires antiviral therapy, based on the predictive efficacy of ALT for disease prognosis. So in this study, we aim at comprehensively evaluating the characteristics of histological abnormalities by a large population of Chinese CHB patients with normal ALT, selecting clinical threshold of ALT to distinguish significantly higher rate of SLHI.

\section{Methods}


A total of 768 consecutive chronic HBV infection patients who underwent liver biopsies and routine laboratory tests at Beijing Youan hospital, Capital Medical University between January 2018 and January 2021 were retrospectively screened for inclusion in the study. Chronic HBV infection was defined as the persistent presence of serum HBV surface antigen (HBsAg) for more than 6 months ${ }^{[6]}$. The included subjects were treatment-naive patients with PNALT levels defined as normal ALT (ULN:Male $\leqq 50 \mathrm{U} / \mathrm{L} ;$ Female $\leqq 40$ IU/L) measured on at least three occasions at intervals of more than 2 months apart over a period of 12 or more months before liver biopsy. Patients with the following conditions were excluded from this study: significant alcohol consumption (>20 g/day) (47 patients); accompanied by non alcoholic fatty liver disease ( 99 patients); accompanied by autoimmune liver disease (27 patients); co-infection with hepatitis $C$ virus, hepatitis $D$ virus, or human

immunodeficiency virus (48 patients); prior or current antiviral treatment (52 patients); and ALT>1×ULN (148 patients). Finally, as shown in Fig.1, 347 treatment-naive chronic HBV infection patients with PNALT levels were included. The study protocol was permitted by the ethics committee of Beijing Youan hospital, Capital Medical, and the procedures were in accordance with the Helsinki declaration of 1975, as revised in 1983(The Code of Ethic Approval:[2020]089).

\section{Liver histological examination}

Ultrasonography-guided percutaneous liver biopsy was performed using a $16 \mathrm{G}$

disposable needle (Hepafix, B. Braun, Melsungen, Germany) under local anesthesia.

Liver samples of minimum length $15 \mathrm{~mm}$ were immediately fixed with $10 \%$ formalin and embedded with paraffin. Liver tissue with at least six portal tracts was considered

sufficient for histological scoring. The METAVIR scoring system was adopted as the

diagnosis standard of liver inflammation and fibrosis according to the recommended standards of Chinese guidelines of the $\mathrm{CHB}$ prevention and treatment (2019 version) ${ }^{[6]}$. Histological grading of liver inflammation is classified into G0 G4, and fibrosis was staged from F0 to F4. significant liver histological injury (SLHI) were defined as

inflammation grade $\geqq 2(\geqq G 2)$ and/or fibrosis stage $\geqq 2(\geqq S 2)$. All biopsy samples were interpreted independently by two liver pathologists. If they failed to reach an agreement, a third highly experienced pathologist reviewed the liver biopsy samples and the results were given by joint discussion of three pathologists.

\section{Laboratory tests}

Fasting blood samples were obtained, and routine laboratory tests were performed at the time of liver biopsies. The serological markers of HBV were detected with commercially available enzyme-linked immunosorbent assay (ELISA) kits (ARCHITECT i2000 SR; Abbott, Wiesbaden, Germany). The serum biochemical parameters including ALT, aspartate transaminase (AST), alkaline phosphatase (ALP), gamma-gluttony transpeptidase (GGT), total bilirubin, albumin, and globulin were measured by full automation biochemistry analyzer (7600 Series; Hitachi, Tokyo, Japan). Routine blood test including white blood cell (WBC) count and platelet count was evaluated with an automated hematology analyzer (XT2000i, Sysmex, Kobe, Japan). HBV DNA was quantified by the real-time PCR system (ABI 7500; Applied Biosystems, Foster City, CA, USA) with the lowest detection limit at $20 \mathrm{IU} / \mathrm{ml}$.

\section{Statistical analysis}

Normality tests of all data were performed by Kolmogorov-Smirnov test. The baseline characteristics of enrolled patients are presented as follows: normal distribution data as mean \pm standard deviation, non-normal distribution continuous data as median (interquartile range), and categorical variables as number (percentage). Chi-square test (for categorical variables), Mann-Whitney test (for non-normal distribution continuous variables), and t-test (for normal distribution variables) were performed to identify statistical differences between groups. Univariate and multiple logistic regression analyses were performed to identify the independent predictors of SLHI. All significance tests were two-tailed, and $\mathrm{p}<0.05$ was considered statistically significant. All statistical analyses were carried out using the SPSS statistical software version 23.0 (SPSS Inc., Chicago, Illinois, USA).

\section{Results}

\section{Baseline characteristics of enrolled patients}

A total of 347 chronic HBV infection patients were enrolled, and baseline characteristics were summarized in Table 1. The majority of enrolled patients were male (210,60.5\%), HBeAg positive (200, 57.64\%) and middle-aged [38 (16-66) years]. Median HBV DNA, ALT, AST, ALP, GGT, albumin, 
globulin, and PLT were 5.4 log10 IU/ml (IQR=0-9.73), $26.3 \mathrm{U} / \mathrm{L}$ (IQR=5-50), $23.2 \mathrm{U} / \mathrm{L}$ (IQR=3-68), $70 \mathrm{U} / \mathrm{L}$ (IQR=59-85), 22 U/L (IQR=13-28), 43 g/L (IQR=41-47), and $206 \times 10^{9} / \mathrm{L}(\mathrm{IQR}=178-298)$, respectively.

Among 347 enrolled patients, 200 (57.64\%) had HBeAg positive and 147 (42.36\%) had HBeAg negative.The immune states of patients with CHB were defined according to Chinese 2019 Hepatitis B Guidance.The distribution of different immune states was as follows: Group A: Immune tolerant CHB(HBeAg positive, HBV DNA囚10 IU/ml), 108 (31.12\%) patients; Group B: HBeAg-positive mild DNA load(HBV DNA $10^{4} \sim 10^{7}$ IU/ml), 72 (20.75\%) patients; Group C: HBeAg-positive low DNA load(HBV DNA $\otimes 10^{4}$ IU/ml), 20 (5.77\%) patients; Group D: HBeAg-negative high DNA load(HBV DNA囚2000IU/ml), 86 (24.78\%) patients; Group E:HBeAg-negative inactive (HBV DNA囚2000IU/ml), 61 (17.58\%) patients.

There was no significant difference in sex,BMI,ALP,GGT,PLT among five groups. The HBeAg negative patients,especially for high HBV DNA load

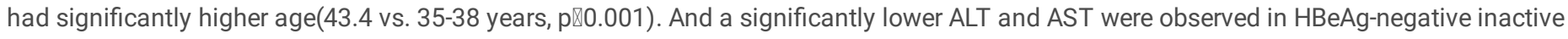
patients with lower HBV DNA load. (22.07 vs 26.7-28.6 U/L , $\mathrm{p}<0.001 ; 19.8$ vs 22.1-27.4 U/L, $\mathrm{p}<0.001$ ). Meanwhile, most of patients with HBeAgpositive and more than $10^{7} \mathrm{IU} / \mathrm{ml}$ HBV DNA load were male, compared with lower HBV DNA load(70.7\% vs. 58.3\%, p=0.048).

\section{Prevalence of significant liver histopathology}

The histopathological data of the liver biopsy samples are shown in Table2. The majority of patients had minimal histological disease: $67.1 \%$ (Histological grading of liver inflammation G1) of the patients, while $29.1 \%$ of the patients had G2 , 3.5\% had G3, only 1 patient had G4, which $32.9 \%$ patients had significant inflammation( $\geqq G 2)$ totally. Regarding liver fibrosis, 26 patients were S0 (7.5\%), 193 were S1(55.6\%), 84 were S2 (24.4\%), 37 were S3 (10.7\%), 7 were S4 (2\%),which $36.9 \%$ patients had significant fibrosis( $\geqq$ S2) totally. In addition, 174 patients had significant liver histological injury (SLHI) defined as $\geqq G 2$ and/or S2,the proportion was $50.1 \%$.

The distributions of the inflammation and fibrosis stage among five groups are shown in Table2 and Fig.2. Significant differences in liver inflammation were observed in HBeAg-positive with less than $10^{7} \mathrm{IU} / \mathrm{ml}$ DNA load, especially for less than 104 $\mathrm{IU} / \mathrm{ml}$ patients(45.8\% 50\% vs. $18 \% \sim 31.4 \%, X^{2}=23.65, p=0.02$ ). This trend was observed in liver fibrosis between HBeAg-positive or negative with high and low DNA load(fig.2A). Actually, the proportion of $\geqq S 2$ in HBeAg-positive patients with mild or low DNA load and in HBeAg-negative patients with high DNA load were significantly higher, compared with other groups(44.44\% 70\% vs. $\left.23.1 \% \sim 27.9 \%, X^{2}=25.5, p=0.001\right)($ fig. $2 B$ ). In the HBeAg-positive patients cohort $(n=200)$, overall proportion of SLHI was 50.5\%(101/200). Based on different levels of HBV DNA load, the subjects were stratified into five groups, namely $>7 \log (54 \%, 108 / 200), 6 \sim 7 \log (15 \%, 30 / 200), 4 \sim 6 \log (21 \%, 42 / 200)$ and $<4 \log (10 \%, 20 / 200)$, and liver biopsies with SLHI in the different age groups are depicted in Fig 2C: $39.8 \%$ of patients with>7log DNA load had SLHI(43/108), and followed by HBV DNA load decreased, 60 70\% of subjects $(18 / 30,26 / 42,14 / 20)$ had SLHI $\left(X^{2}=11.2, P=0.01\right)$. As for HBeAg-nagtive patients( $\left.n=147\right)$, overall proportion of SLHI was 49.7\%(73/147). Based on different levels of HBV DNA load, the subjects were stratified into five groups, namely $<2000(41.5 \%, 61 / 147), 2000 \sim 4 \log (28.6 \%, 42 / 147)$, $4 \sim 5 \log (15 \%, 22 / 147)$ and $>5 \log (15 \%, 22 / 147)$. In contrast with HBeAg-positive patients, SLHI rate in HBeAg-negative inactive (HBV DNA囚 $2000 \mathrm{IU} / \mathrm{ml}$ ) was significantly lower(39.8\%),compared with higher HBV DNA load patients(50\% 77.3\%, $\left.\mathrm{X}^{2}=10.4, \mathrm{P}=0.02\right)(\mathrm{Fig} .2 \mathrm{D})$.

\section{Analysis of Factors Associated with significant liver histological injury (SLHI) in}

\section{HBeAg-Positive and -Negative Patients with PNALT}

When the presence or absence of SLHI was considered as a binary dependent variable in HBeAg-positive and -negative patients with PNALT, univariate analysis indicated that ALT, AST, HBV DNA, HBeAg, HBsAg and Fibroscan were associated with SLHI in HBeAg-positive and -negative patients with PNALT, respectively (Supplymentary Tables 1). However, multiple logistic regression analysis indicated that HBsAg and Fibroscan were associated with SLHI in HBeAg-positive patients with PNALT, and AST, HBsAg and Fibroscan were the associated factors in HBeAg-negative patients.(Supplymentary Tables 1 and 2).

\section{Area Under the Curve (AUC) of some factors Associated with Significant Histological Abnormalities in HBeAg-Positive and -Negative Patients}

Receiver operating characteristic (ROC) analysis was used to investigate the predictive ability of LSM and clinical data of SLHI from biopsy reports in patients with $\mathrm{CHB}$ (Supplymentary Table 2). Among patients with a normal ALT level, the AUC of the ALT level associated with the diagnosis of SLHI was 0.572 and 0.6 in female and male patients,respectively (Female:cut-off value was 20U/L,95\% confidence interval [CI], 0.48-0.67; sensitivity $=60 \%$, specificity $=55 \%$;Male: cut-off value was $25 \mathrm{U} / \mathrm{L}$, sensitivity $=66 \%$, specificity $=54 \%$ ). Totally, the AUROC of the LSM predicting SHLI risk $(0.753$, cut-off value $6 \mathrm{Kpa}$, sensitivity $=59.2 \%$, specificity $=82.7 \%)$ was higher than that of age $(0.57$, cut-off value $40 \mathrm{years})$, male $(0.48, \mathrm{P}=$ 0.031), AST(Female: 0.64 ,cut-off value 22U/L;Male: 0.63,cut-off value 30U/L). In the HBeAg-positive patients, AUROC for HBeAg and HBsAg predicting SLHI were 0.66(cut-off value 104.45COI) and 0.67(cut-off value $4 \mathrm{log} 10 \mathrm{IU} / \mathrm{m}$ ), respectively. For HBeAg negative patients, the AUROC for HBsAg was 0.626 with cut-off value $2.86 \log 10 \mathrm{IU} / \mathrm{ml}$. As for HBV DNA load, the AUROC were 0.63 and 0.65 in HBeAg positive and negative patients,respectively. The cut-off value were less the $7 \mathrm{log} 10 \mathrm{IU} / \mathrm{ml}$ in HBeAg positive patients and more than $3.3 \mathrm{log} 10 \mathrm{IU} / \mathrm{ml}$.

Among the 347 chronic HBV infection patients with a normal serum ALT, 
only 150 patients (43.23\%,Fig3A) had an ALT level within our cut-off value reference ranges (i.e. $25 \mathrm{U} / \mathrm{L}$ for men and $20 \mathrm{U} / \mathrm{L}$ for women). Among these 150 patients, only 60 (40\%) showed SLHI. A comparison of SLHI between those with ALT levels within the our criteria and those exceeding the our criteria among all 347 patients is shown in Figure 3B. Patients with ALT levels exceeding the our criteria were more likely to have SLHI ( $57.9 \%$ vs. $40 \%$, p=0.001,Fig.3B).Especially for the HBeAg-positive patients with lower HBV DNA loads and HBeAg-negative patients with higher HBV DNA loads. After revising the ULN of ALT according to our criteria(25 U/L for men and $20 \mathrm{U} / \mathrm{L}$ for women), the proportion of SLHI in patients

within ALT criteria(<25 U/L for men and <20 U/L for women) and high HBV DNA loads(>7log10IU/ml)was significantly lower, compared with patients having lower HBV DNA loads( $\leqq 7 \log 10 \mathrm{IU} / \mathrm{ml})$ with exceeding ALT criteria(25 50U/L for men and 20 40U/L for women)(33.3\% vs. 67\%, $\mathrm{X}^{2}=17.78, \mathrm{P}=0.001$,Fig.3C). Again, there was significant difference in proportion of SLHI between patients within ALT criteria and less than $2000 \mathrm{IU} / \mathrm{ml}$ of HBV DNA loads (32\%) and exceeding ALT criteria with more than $2000 \mathrm{IU} / \mathrm{ml}\left(70 \%, \mathrm{X}^{2}=12.11, \mathrm{P}=0.006, \mathrm{Fig} .3 \mathrm{D}\right)$.

\section{Development of combination indexes estimating significant liver histological injury risk}

For totally patients, based on the above single variables, combination indexes were necessary to be constructed to explore whether performance could be improved through logistic analysis. Finally, we developed a novel combination indexes consisting age, LSM, ALT, AST, HBsAg, HBeAg and HBV DNA load according to the classical diagnostic test, and each value was the cut-off value described above. For HBeAg-positive patients, it

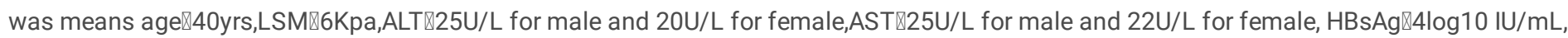
HBeAg $\otimes 104.45 \mathrm{COI}, \mathrm{HBV} D N A$ load $\otimes 7 \log 10 \mathrm{IU} / \mathrm{ml}$,each item was assigned one point. Logit(P) $=-1.8+0.5^{\star} \mathrm{Age}-0.4^{\star} \mathrm{ALT}+1.3^{*} \mathrm{AST}+1.1^{\star} \mathrm{HBeAg}+$ $1 * \mathrm{HBsAg}-0.1 * \mathrm{HBV}$ DNA+1.9*LSM.The AUROC of the combination indexes was 0.822 with Positive Predictive Value(PPV) $85.92 \%$ and negative predictive value (NPV) $70 \%$ (95\% Cl 0.764-0.879), which was higher than any single indicator and the cut-off value was 0.56(Fig.4A).For example,a 43 years HBeAg-positive male patient, who has ALT of 38U/L and AST 32U/L, with HBsAg of 4.8log10IU/ml, HBeAg of 118COI and HBV DNA load of $7.2 \log 10 \mathrm{lU} / \mathrm{ml}$, was 3.3 points base on each item was assigned one point. Therefore, the patient was considered to have SLHI even without biopsy-proven and should be received antiviral therapy.

Among the HBeAg-negative patients, except for the general indicators(age, ALT,AST and LSM), HBsAg and HBV DNA load were adjusted into the The final formula(each factor was ascribed as one point total that implied a possibility of SLHI presence), as follows: Logit(P)=-1.7-

$0.1 * \mathrm{Age}+0.2 * \mathrm{ALT}+0.7 * \mathrm{AST}+1.1 * \mathrm{HBsAg}+0.2 * \mathrm{HBV}$ DNA+1.7* LSM. The AUROC of the combination indexes was 0.818 with PPV $77.65 \%$ and NPV

$71.69 \%(95 \% \mathrm{Cl} 0.750-0.885)$, which was higher than any single indicator and the cut-off value was 0.53(Fig.4B).

\section{Discussion}

The results of the present study demonstrate that chronic HBV infections with persistently normal ALT (PNALT) levels do not always display no or only minimal histologic injury. The present data indicated that 50.1\% (174/347) of patients had significant liver histological injury (SLHI) defined as $\geqq G 2$ and/or S2, which was consistent with three reports from China, USA and India, which reported 37-68.6\% ${ }^{[15-17]}$. These results are notable: as for the invasive nature of liver biopsy, in clinical practice, physicians have primarily used ALT levels as a convenient surrogate marker of liver damage, even if clinical guidelines recommend that liver biopsy was the gold standard for assessing SLHI. Finally, patients with PNALT should not undergo treatment; consequently, these patients are often ignored.

In order to determine the antiviral treatment trigger point and improve survival rates, various treatment guidelines require a certain ALT threshold to rapidly identify patients with $\mathrm{CHB}$ at risk of developing SLHI and for treatment decisions.Current ULN for ALT level were set, on average, at $40 \mathrm{U} / \mathrm{L}$ in studies conducted over the past 10 years. Such threshold was adopted by EASL ${ }^{[2]}$ and APASL ${ }^{[18]}$ as a crucial criterion for determining treatment initiation for CHB. As for AASLD ${ }^{[5]}$,the ULN of $35 \mathrm{U} / L$ ALT for male and $25 \mathrm{U} / \mathrm{L}$ for female adults is recommended when guiding management decisions, which can improve disease outcome. Interestingly, we found that the AUC of the ALT associated with the diagnosis of SLHI was 0.572 for female and 0.6 for male with a cut-off value of $20 \mathrm{U} / \mathrm{L}$ and $25 \mathrm{U} / \mathrm{L}$, respectively $(p=0.04, p=0.013$ ). Our finding of cut-off value for ALT level was equivalent to that recommended by APASL guidelines that ALT level is divided into high-(0.5-1 $\times$ ULN) and low-normal $(\leq 0.5 \times U L N)$ ALT. Base on the new threshold, $43.23 \%$ of patients (150/347) was categorized into low-normal ALT and proportion of SLHI was significantly lower, compared to the patients exceeding the our criteria(40\% vs. $57.9 \%, p=0.001)$.

Except for ALT level, HBeAg status and HBV DNA levels were the important factors to judge the immune status of patients with CHB, which was helpful to evaluate the liver histology, prognosis of the disease and make treatment decision ${ }^{[19]}$.In our study, with respect to SLHI, the HBV DNA level had reached statistical significance with an AUROC of 0.63 and 0.65 at a level of below $7 \mathrm{log} \mathrm{IU} / \mathrm{ml}$ in $\mathrm{HBeAg}$-positive and over $2000 \mathrm{IU} / \mathrm{ml}$ in HBeAg-nagetive patients. In HBeAg-positive patients, proportion of SLHI in the high normal ALT(0.5 1ULN) group with lower HBV DNA(< 7log10 $\mathrm{IU} / \mathrm{ml}$ )has risen to double, compared to the low normal $\mathrm{ALT}(<0.5 \mathrm{ULN})$ group with high $\mathrm{HBV} \mathrm{DNA}(\geqq 7 \log 10 \mathrm{IU} / \mathrm{ml})(66.7 \% \mathrm{vs} 33.3 \%, \mathrm{p}<0.01)$.It is interesting that the latter one was belong to immune tolerant $\mathrm{CHB}$ which was defined as HBeAg positive, with $\mathrm{HBV}$ DNA囚107 IU/ml in Chinese guidelines, but more rigorous. In the same way, this can be also seen in HBeAg-negative patients with HBV DNA levels at < 2000 IU/ml which are commonly known as "inactive carriers",and significant liver fibrosis was rare with an estimated rate of $10 \%$ [20]. However, our results showed that $37.7 \%$ of "inactive carriers" had SLHI totally, among these patients, $70 \%$ in patients with high-normal ALT and $32 \%$ in low-normal ALT (P<0.001).

Page 5/12 
In the light of international guidelines such as the AASLD and APASL, as well as Chinese Guidelines (2019), antiviral treatment is not recommended for IT-CHB and inactive carriers ${ }^{[5,6,18]}$. However, more studies had reported using only ALT and HBV DNA levels to define these might mis-classify a fair proportion of gray zone(GZ) patients with significant liver histopathology ${ }^{[21]}$. In our study, higher proportion (51.3\%) of GZ was reported which including $26.52 \%$ of patients with HBeAg positive and HBV DNA $<7 \mathrm{log} 10 \mathrm{IU} / \mathrm{ml}$, whereas $24.78 \%$ with $\mathrm{HBeAg}$ negative and $\mathrm{HBV}$ DNA $>2000 I U / m l$, using conventional ALT criteria with the cut-off of $40 \mathrm{U} / \mathrm{L}$ for women and 50U/L for men.The proportion of SLHI were significantly high in the GZ

patients, range from $60 \sim 77.3 \%$. Therefore, we should pay more attention to find GZ and optimize the management. Several researchers suggested to revise the ULN of ALT. Prati et al. had recommended that the ULN for ALT should be decreased to $30 \mathrm{U} / \mathrm{L}$ for men and $19 \mathrm{U} / \mathrm{L}$ for women [22], Lee et al. also proposed reducing the

ULN of ALT to $35 \mathrm{U} / \mathrm{L}$ for men and $25 \mathrm{U} / \mathrm{L}$ for women ${ }^{[23]}$. Similar to our results, the previous studies also had the evidence to revise the ULN of ALT by discovering that high-normal ALT patients had more significant liver histopathology ${ }^{[24]}$. Gui et al[25] found a significant higher prevalence of liver histopathology in the high-normal ALT group of CHB patients than in the low-normal ALT group (40.0\% vs $16.6 \%$, p $<0.01)$, suggesting that a higher proportion of patients with high-normal ALT may have risk of disease progression.

Finally,in order to develop a noninvasive mathematical model to replace liver biopsy to determine SLHI in chronic HBV infection patients, we developed a nomogram that predict SLHI risk according to 7 routine available variables. The predictive value of the nomogram was extremely high with PPV 85.92\%,NPV 70\% in HBeAg-positive patients and PPV 77.65\%, NPV 71.69\% in HBeAg-positive patients. Notably,except for ALT, HBV DNA loads discussed above, age $>40 \mathrm{yrs}, \mathrm{LSM} \otimes 6 \mathrm{Kpa}, \mathrm{HBsAg}$ and $\mathrm{HBeAg}$ were rapid and easy to perform in clinical practice. Age is a vital factor affecting the natural course and long term outcomes of patients with chronic HBV infection, and the incidence of adverse events increase with age $[26,27]$. In addition, the HBeAg-positive phase of $\mathrm{CHB}$ is usually associated with viral repli

cation and hepatitis activity ${ }^{[28,29]}$.Persistent presence of HBeAg has been demonstrated to be associated with a higher risk of fibrosis progression and cirrhosis development.Therefore, it is important for clinicians to monitoring disease progression in GZ CHB patients with older age and highnormal ALT who might have higher risk of advanced disease

There were several limitations that affected the interpretation of our findings. This study was a retrospective cross-sectional study that could not exclude selection bias of patients. Moreover, the number of patients aged 50 years was relatively small, and follow-up of patients after liver biopsy was insufficient. Findings of this study could not be generally applied to the genotype other than genotype B.

\section{Declarations}

\section{Author Contribution}

Ren Shan and Chen Xinyue contributed to the conception of the study;Wang Kefei and Zheng Yanhong contributed to the collection of the clinical data; Ren Shan and Lu Jufeng contributed significantly to analysis and manuscript preparation;Ren Shan and Ma Lina performed the data analyses and wrote the manuscript; Chen Xinyue and Zheng Sujun helped perform the analysis with constructive discussions.

\section{Funding}

We are grateful to all the subjects who participated in this study. This work was supported by the Capital Health Development Scientific Research Project(2020-1-2181); You an Foundation of Liver Disease and AIDS(YNKTQN20180209,BJYAYY-2020CX-01, BJYAYY-2020ZQN-01); Bethune Medical Science Research Foundation(SG095FN).The funders had no role in the study design, data collection and analysis, decision to publish, or preparation of the manuscript.

\section{Availability of data and materials}

The data used to support the findings of this study are available from the corresponding author upon request.

\section{Consent to Participate (Ethics)}

The study protocol was permitted by the ethics committee of Beijing Youan hospital, Capital Medical, China, and the procedures were in accordance with the Helsinki declaration of 1975, as revised in 1983(The Code of Ethic Approval:[2020]089)

\section{Consent for publication(Ethics)}

Ethics Committee approval was obtained from the Institutional Ethics Committee of Capital Medical University Beijing Youan hospital to the commencement of the study. 


\section{Competing interests}

The authors declared no conflict of interests.

\section{Author details}

1 First Department of Liver Disease,Beijing Youan hospital,Capital Medical University,Beijing100069,China

\section{References}

1. World Health Organization. Global Hepatitis Report 2017. 2017; http://www.who.int/hepatitis/publications/global-hepatitis-report2017/en/.

2. European Association for the Study of the Liver. EASL 2017 Clinical Practice Guidelines on the management of hepatitis B virus infection[J]. J Hepatol, 2017, 67(2):370-98. DOI: 10.1016/j.jhep.2017.03.021.

3. Parikh P, Ryan JD, Tsochatzis EA. Fibrosis assessment in patients with chronic hepatitis B virus (HBV)infection. Annals of Translational Medicine. 2017; 5(3):1-14. https://doi.org/10.21037/atm.2017.01.28 PMID: 28251119.

4. Kew MC. Serum aminotransferase concentration as evidence of hepatocellular damage. The Lancet.2000; 355(9204):591-2. https://doi.org/10.1016/S0140-6736(99)00219-6 PMID: 10696975

5. TERRAULT NA, LOK ASF, MCMAHON BJ, et al. Update on prevention, diagnosis, and treatment of chronic hepatitis B: AASLD 2018 hepatitis B guidance. Hepatology[J], 2018, 67(4):1560-99. DOI: 10.1002/hep.29800.

6. Chinese Society of Infectious Diseases, Chinese Medical Association; Chinese Society of Hepatology, Chinese Medical Association. Guidelines

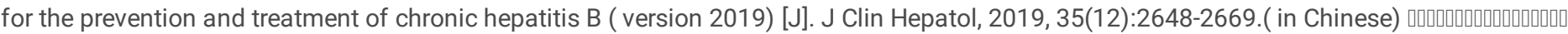
Q

7. Kim HC, Nam CM, Jee SH, Han KH, Oh DK, Suh I. Normal serum aminotransferase concentration and risk of mortality from liver diseases: prospective cohort study. BMJ 2004; 328:983 [PMID: 15028636 DOI: 10.1136/bmj.38050.593634.63]

8. Kariv R, Leshno M, Beth-Or A, Strul H, Blendis L, Kokia E, Noff D, Zelber-Sagie S, Sheinberg B, Oren R, Halpern Z. Re evaluation of serum alanine aminotransferase upper normal limit and its modulating factors in a large-scale population study. Liver Int 2006; 26: 445-450 [PMID: 16629648 DOI: 10.1111/j.1478-3231.2006.01197.x]

9. Van der Poorten D, Kenny DT, Butler T, George J. Liver disease in adolescents: A cohort study of high-risk individuals. Hepatology 2007; 46: 1750-1758 [PMID: 18023024 DOI: 10.1002/hep.21918]

10. Emmet B. Keeffe,Douglas T. Dieterich,Steven-Huy B. Han,Ira M. Jacobson,Paul Martin,Eugene R. Schiff,Hillel Tobias,Teresa L. Wright. A Treatment Algorithm for the Management of Chronic Hepatitis B Virus Infection in the United States: An Update[J]. Clinical Gastroenterology and Hepatology,2006,4(8):936-962.DOI: 10.1016/j.cgh.2006.05.016

11. Gi-Ae Kim,Young-Suk Lim,Seungbong Han,Jonggi Choi,Ju Hyun Shim,Kang Mo Kim,Han Chu Lee,Yung Sang Lee. High risk of hepatocellular carcinoma and death in patients with immune-tolerant-phase chronic hepatitis B[J]. Gut,2018,67(5):945-952.DOI: 10.1136/gutjnl-2017-314904

12. Montazeri Ghodrate,Rahban Maryam,Mohamadnejad Mehdi,Zamani Farhad,Hooshyar Afshin,Fazlolahi Atoosa,Abedian Shifteh,Ghoujeghi Farhad,Estakhri Arezoo,Montazeri Farhad,Razjoyan Hadi,Mamarabadi Mansoureh,Alimohamadi Meysam,Tavangar Seyed Mohamad,Malekzadeh Reza. Liver histology and HBV DNA levels in chronically HBV infected patients with persistently normal alanine aminotransferase.[J]. Archives of Iranian medicine,2010,13(3):193-202.PMID: 20433223

13. Göbel Thomas,Erhardt Andreas,Herwig Mathias,Poremba Christopher,Baldus Stephan Ernst,Sagir Abdurrahman,Heinzel-Pleines Ulrike,Häussinger Dieter. High prevalence of significant liver fibrosis and cirrhosis in chronic hepatitis B patients with normal ALT in central Europe.[J]. Journal of medical virology,2011,83(6):968-973.DOI: 10.1002/jmv.22048

14. SHANG Hong,CHEN Wen-xiang,PAN Bo-shen,et al.Reference intervals for common tests of liver function, electrolytes and blood cell analysis of

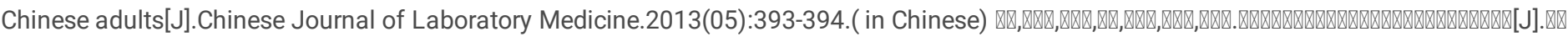
囚,2013(05):393-394.

15. LIAO B, WANG Z, LIN S, et al. Significant fibrosis is not rare in Chinese chronic hepatitis B patients with persistent normal ALT[J]. PLoS One, 2013, 8(10):e78672. DOI: 10.1371/journal.pone.0078672

16. XING YF, ZHOU DQ, HE JS, et al. Clinical and histopathological features of chronic hepatitis B virus infected patients with high HBV-DNA viral load and normal alanine aminotransferase level: A multicentre-based study in China[J]. PLoS One, 2018, 13(9):e0203220. DOI: 10.1371/journal.pone.0203220.

17. CHEN CF, LEE WC, YANG HI, et al. Changes in serum levels of HBV DNA and alanine aminotransferase determine risk for hepatocellular carcinoma[J]. Gastroenterology, 2011, 141(4):1240-8, 8.e1-2. DOI: 10.1053/j.gastro.2011.06.036. 
18. K. Sarin,M. Kumar,G. K. Lau,Z. Abbas,H. L. Y. Chan,C. J. Chen,D. S. Chen,H. L. Chen,P. J. Chen,R. N. Chien,A. K. Dokmeci,Ed Gane,J. L. Hou,W. Jafri,J. Jia,J. H. Kim,C. L. Lai,H. C. Lee,S. G. Lim,C. J. Liu,S. Locarnini,M. Al Mahtab,R. Mohamed,M. Omata,J. Park,T. Piratvisuth,B. C. Sharma,J. Sollano,F. S. Wang,L. Wei,M. F. Yuen,S. S. Zheng,J. H. Kao. Asian-Pacific clinical practice guidelines on the management of hepatitis B: a 2015 update[J]. Hepatology International,2016,10(1)®1-98.

19. McMahon BJ. The natural history of chronic hepatitis B virus infection. Hepatology. 2009; 49(S5):S45-S55. https://doi.org/10.1002/hep.22898

20. Papatheodoridis GV, Manolakopoulos S, Liaw YF, Lok A. Follow-up and indications for liver biopsy in HBeAg-negative chronic hepatitis B virus infection with persistently normal ALT: a systematic review. J Hepatol. 2012;57(1):196-202.

21. Bonacci M, Lens S, Mariño Z, et al. Anti-viral therapy can be delayed or avoided in a significant proportion of HbeAg-negative Caucasian patients in the Grey Zone. Aliment Pharmacol Ther. 2018;47(10):1397-1408.

22. Prati Daniele,Taioli Emanuela,Zanella Alberto,Della Torre Emanuela,Butelli Sonia,Del Vecchio Emanuela,Vianello Luciana,Zanuso Francesco,Mozzi Fulvio,Milani Silvano,Conte Dario,Colombo Massimo,Sirchia Girolamo. Updated definitions of healthy ranges for serum alanine aminotransferase levels.[J]. Annals of internal medicine,2002,137(1):pp11-10.DOI: 10.7326/0003-4819-137-1-200207020-00006

23. LEE HW, CHAN HL. Unresolved issues of immune tolerance in chronic hepatitis B[J]. J Gastroenterol. 2020, 55(4):383-9. DOI: 10.1007/s00535020-01665-Z.

24. Duan Menghui,Chi Xiaoling,Xiao Huanming,Liu Xueen,Zhuang Hui. High-normal alanine aminotransferase is an indicator for liver histopathology in HBeAg-negative chronic hepatitis B.[J]. Hepatology international,2021,15(2):318-327.

25. Gui HL, Wang H, Yang YH, Wu YW, Zhou HJ, Guo SM, et al. Significant histopathology in Chinese chronic hepatitis B patients with persistently high-normal alanine aminotransferase. Journal of Viral Hepatitis. 2010; 17:44-50. https://doi.org/10.1111/j.1365-2893.2010.01270.x

26. Bonacci M, Lens S, Mariño Z, et al. Anti-viral therapy can be delayed or avoided in a significant proportion of HbeAg-negative Caucasian patients in the Grey Zone. Aliment Pharmacol Ther. 2018;47(10):1397-1408.

27. Choi GH, Kim G-A, Choi J, Han S, Lim Y-S. High risk of clinical events in untreated HbeAg-negative chronic hepatitis B patients with high viral load and no significant ALT elevation. Aliment Pharmacol Ther. 2019;50(2):215-226.

28. Sonneveld MJ, Brouwer WP, Chan HLY, et al. Optimisation of the use of APRI and FIB-4 to rule out cirrhosis in patients with chronic hepatitis B: results from the SONIC-B study. Lancet Gastroenterol Hepatol. 2019;4(7):538-544.

29. Shan S, You H, Niu J, et al. Baseline characteristics and treatment patterns of the patients recruited to the china registry of hepatitis B. J Clin Transl Hepatol. 2019;7(4):322-328

\section{Tables}

Table 1. Baseline characteristics of enrolled patients. 


\begin{tabular}{|c|c|c|c|c|c|c|c|}
\hline \multirow[t]{2}{*}{$\begin{array}{l}\text { Clinical } \\
\text { characteristics }\end{array}$} & \multirow[t]{2}{*}{$\begin{array}{l}\text { Total } \\
(n=347)\end{array}$} & \multicolumn{3}{|c|}{ HBeAg-positive patients } & \multicolumn{3}{|c|}{$\begin{array}{l}\text { HBeAg-negative patients } \\
(n=147,42.36 \%)\end{array}$} \\
\hline & & $\begin{array}{r}\text { Group A } \\
(n=108)\end{array}$ & $\begin{array}{l}\text { Group B } \\
(n=72)\end{array}$ & $\begin{array}{l}\text { Group C } \\
(n=20)\end{array}$ & $\underset{(n=86)}{\operatorname{Group}} \mathrm{D}$ & $\begin{array}{l}\text { Group } E \\
(n=61)\end{array}$ & Value \\
\hline Age(Year) & $38.91 \pm 9.62$ & $35.02 \pm 7.30$ & $37.31 \pm 10.10$ & $38.80 \pm 7.83$ & $43.40 \pm 10.36$ & $41.43 \pm 9.04$ & $F=12.26, p<0.001$ \\
\hline Male n(\%) & $210(60.5 \%)$ & $63(58.3 \%)$ & $49(68.1 \%)$ & $16(80 \%)$ & $23(52.3 \%)$ & $59(62.3 \%)$ & $X^{2}=6.80, p=0.14$ \\
\hline $\mathrm{BMI}\left(\mathrm{kg} / \mathrm{m}^{2}\right)$ & $22.82 \pm 4.23$ & $21.42 \pm 4.23$ & $23.1 \pm 3.92$ & $23.19 \pm 2.10$ & $22.32 \pm 5.12$ & $20.11 \pm 4.12$ & $F=0.28, p=0.34$ \\
\hline $\operatorname{ALT}(\mathrm{U} / \mathrm{L})$ & $26.34 \pm 9.82$ & $28.64 \pm 9.38$ & $28.40 \pm 9.41$ & $26.71 \pm 10.69$ & $24.68 \pm 9.90$ & $22.07 \pm 9.07$ & $F=7.30 p<0.001$ \\
\hline $\mathrm{AST}(\mathrm{U} / \mathrm{L})$ & $23.21 \pm 11.2$ & $22.10 \pm 110.12$ & $27.64 \pm 17.0$ & $23.86 \pm 7.31$ & $23.14 \pm 8.81$ & $19.80 \pm 6.31$ & $F=5.70, p=0.003$ \\
\hline $\operatorname{PLT}\left(10^{9} / \mathrm{L}\right)$ & $206 \pm 78.82$ & $248 \pm 96.00$ & $218 \pm 86.00$ & $211 \pm 72.00$ & $185 \pm 62.00$ & $209 \pm 89.00$ & $F=0.83, p=0.09$ \\
\hline $\operatorname{ALB}(g / L)$ & $43.0 \pm 4.20$ & $45.0 \pm 5.17$ & $43.0 \pm 3.65$ & $43.0 \pm 4.81$ & $44.0 \pm 3.78$ & $41.32 \pm 5.16$ & $F=0.78, p=0.64$ \\
\hline $\operatorname{ALP}(U / L)$ & $70.0 \pm 29.0$ & $72.0 \pm 28.0$ & $73.2 \pm 23.4$ & $69.0 \pm 32.1$ & $76.0 \pm 21.8$ & $71.0 \pm 28.0$ & $F=0.66, p=0.61$ \\
\hline GGT (U/L) & $22.0 \pm 27.0$ & $20.0 \pm 13.0$ & $24.0 \pm 18.0$ & $23.0 \pm 19.8$ & $20.9 \pm 14.8$ & $23.4 \pm 17.0$ & $F=0.59, p=0.56$ \\
\hline Genotype C (n,\%) & $266(76.1 \%)$ & $82(75.92 \%)$ & $54(75)$ & $12(60 \%)$ & $34(77.27 \%)$ & $84(81.53 \%)$ & $x^{2}=3.46, p=0.09$ \\
\hline HBVDNA(log10IU/mL) & $5.40 \pm 2.25$ & $8.14 \pm 0.60$ & $5.60 \pm 0.91$ & $2.81 \pm 1.00$ & $4.40 \pm 1.03$ & $2.57 \pm 0.56$ & $F=655.4, p<0.001$ \\
\hline HBsAg(log10 IU/ml) & $3.55 \pm 0.94$ & $4.07 \pm 0.77$ & $3.62 \pm 0.78$ & $3.44 \pm 0.55$ & $3.23 \pm 0.65$ & $2.86 \pm 1.22$ & $F=22.78, p<0.001$ \\
\hline $\mathrm{HBeAg}(\mathrm{COI} / \mathrm{ml})$ & $565.49 \pm 826$ & $1386.68 \pm 703.65$ & $599.03 \pm 903.1$ & $175.57 \pm 378$ & $0.13 \pm 0.15$ & $0.11 \pm 0.04$ & $F=92.51, p<0.001$ \\
\hline Fibroscan:LSM(Kpa) & $6.14 \pm 4.02$ & $6.10 \pm 6.35$ & $6.44 \pm 2.75$ & $6.34 \pm 2.69$ & $6.46 \pm 2.38$ & $5.31 \pm 1.04$ & $F=13.82, p=0.85$ \\
\hline
\end{tabular}

*BMI:Body mass index;PLT:Platelet counts;ALB:Albumin;ALP:Alkaline phosphatase; GGT: g glutamyltransferase;SLHI:significant liver histological injury, defined as inflammation grade $\geqq 2$ ( $\geqq G 2)$ and/or fibrosis stage $\geqq 2(\geqq F 2$ ).

Table 2. Distribution of liver necroinflammation and fibrosis in different immune states groups (\%)

\begin{tabular}{|c|c|c|c|c|c|c|c|}
\hline $\begin{array}{l}\text { liver } \\
\text { histopathology }\end{array}$ & $\begin{array}{l}\text { Total } \\
(n=347)\end{array}$ & $\begin{array}{r}\text { HBeAg-pos } \\
(n=200,57 .\end{array}$ & patients & & $\begin{array}{l}\text { HBeAg-neg } \\
(n=147,42 .\end{array}$ & patients & values \\
\hline $\begin{array}{l}\text { Inflammation } \mathrm{n} \\
(\%)\end{array}$ & & $\begin{array}{r}\text { Group A } \\
(n=108)\end{array}$ & $\begin{array}{l}\text { Group B } \\
(n=72)\end{array}$ & $\begin{array}{l}\text { Group C } \\
(n=20)\end{array}$ & $\underset{(n=86)}{\text { Group } D}$ & $\underset{(n=61)}{\operatorname{Group}} \mathrm{E}$ & $x^{2}=23.65, p=0.02$ \\
\hline G1 & 233(67.1\%) & $75(69.4 \%)$ & $39(54.7 \%)$ & $10(50 \%)$ & $59(68.6 \%)$ & $50(82 \%)$ & \\
\hline $\mathrm{G} 2$ & 101(29.1\%) & $31(28.1 \%)$ & $27(37.5 \%)$ & $8(40 \%)$ & $24(27.9 \%)$ & $11(18 \%)$ & \\
\hline G3 & $12(3.5 \%)$ & $2(1.9 \%)$ & $6(8.3 \%)$ & $2(10 \%)$ & $2(2.3 \%)$ & $0(0)$ & \\
\hline G4 & $1(0.3 \%)$ & $0(0)$ & $0(0)$ & $0(0.7 \%)$ & $1(1.2 \%)$ & $0(0)$ & \\
\hline$\geqq G 2$ & 114(32.9\%) & $33(30.6 \%)$ & $33(45.8 \%)$ & $10(50 \%)$ & $27(31.4 \%)$ & $11(18 \%)$ & $x^{2}=14.58, p=0.006$ \\
\hline $\begin{array}{l}\text { Fibrosis } \\
\mathrm{n}(\%)\end{array}$ & & & & & & & $x^{2}=36.73, p=0.002$ \\
\hline so & $26(7.5 \%)$ & $9(8.3 \%)$ & $4(5.6 \%)$ & $0(0)$ & $8(9.3 \%)$ & $5(8.2 \%)$ & \\
\hline S1 & 193(55.6\%) & $74(68.5 \%)$ & $36(50 \%)$ & $6(30 \%)$ & $38(44.2 \%)$ & $39(63.9 \%)$ & \\
\hline $\mathrm{S} 2$ & $84(24.2 \%)$ & $16(14.8 \%)$ & $19(26.4 \%)$ & $10(50 \%)$ & $23(26.7 \%)$ & $16(26.2 \%)$ & \\
\hline S3 & $37(10.7 \%)$ & $9(8.3)$ & $10(13.9 \%)$ & $3(15 \%)$ & $14(16.3 \%)$ & $1(1.6 \%)$ & \\
\hline S4 & $7(2 \%)$ & $0(0)$ & $3(4.3 \%)$ & $1(5 \%)$ & $3(3.5 \%)$ & $0(0)$ & \\
\hline$\geqq S 2$ & $128(36.9 \%)$ & $25(23.1 \%)$ & $32(44.4 \%)$ & $14(70 \%)$ & $40(46.5 \%)$ & $17(27.9 \%)$ & $x^{2}=25.5, p=0.001$ \\
\hline SLHI $n(\%)$ & $174(50.1 \%)$ & $43(39.8 \%)$ & $44(61.1 \%)$ & $14(70 \%)$ & $50(58.1 \%)$ & $23(37.7 \%)$ & $X^{2}=17.20, p=0.002$ \\
\hline
\end{tabular}




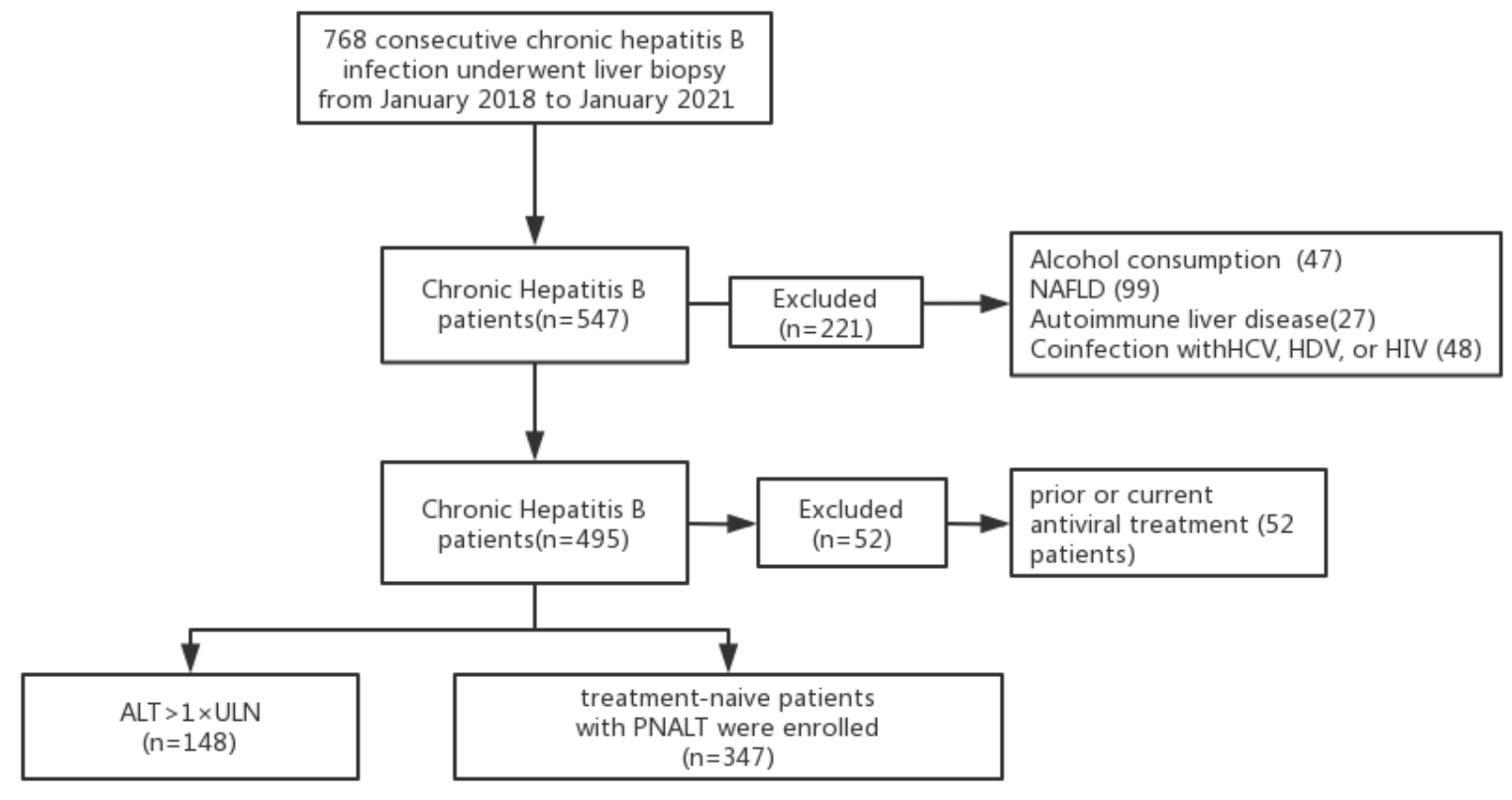

Figure 1

Flow chart of study design(NAFLD: non alcoholic fatty liver disease; HCV:hepatitis C virus;HDV:hepatitis D virus; HIV:human immunodeficiency virus;PNALT:Persistent normal ALT; ULN:Male $\leqq 50 \mathrm{U} / \mathrm{L} ;$ Female $\leqq 40 \mathrm{U} / \mathrm{L})$
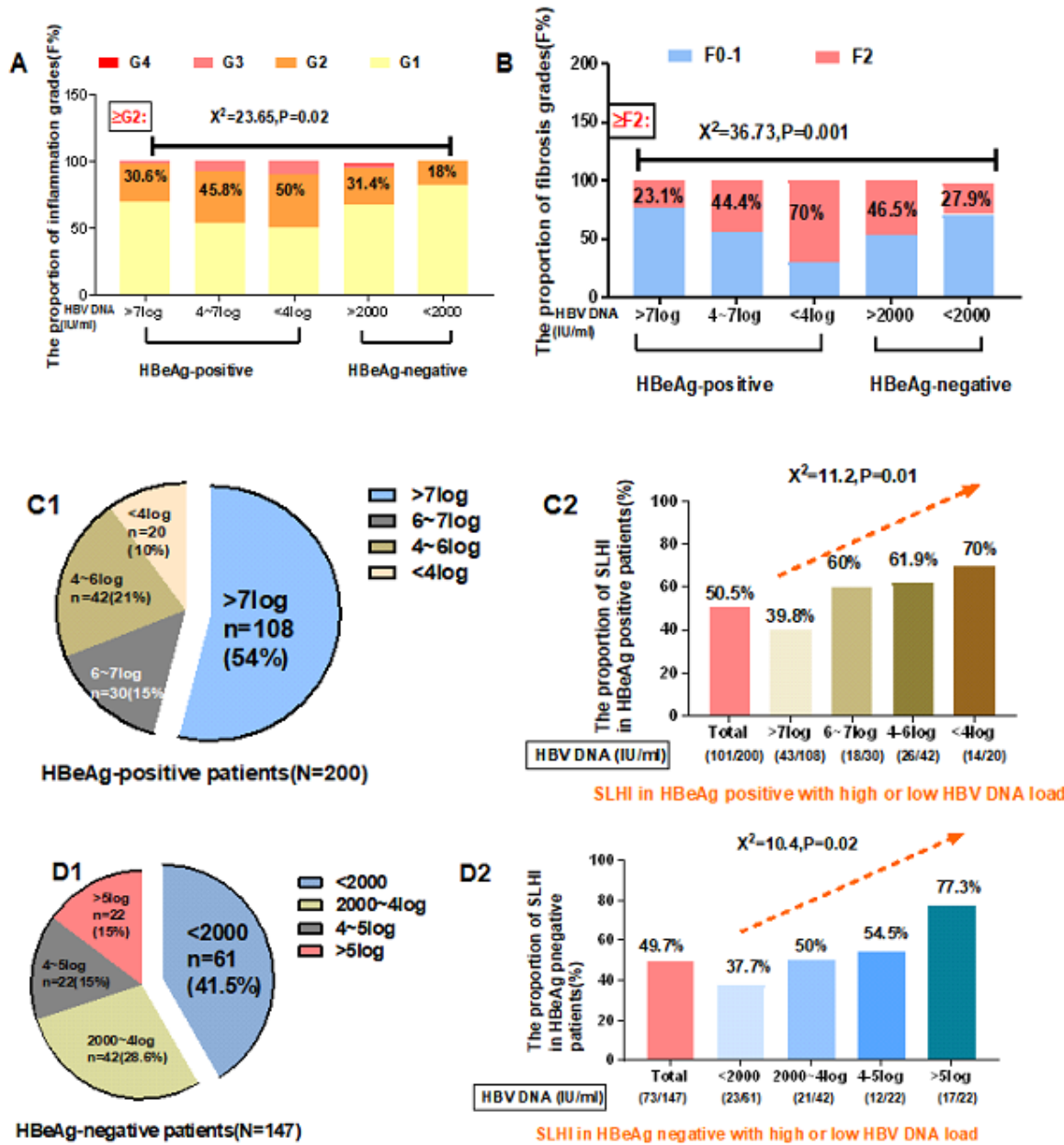
Figure 2

Distribution of liver inflammation and fibrosis in different immune states groups (\%). (A) Significant differences in liver inflammation were observed in all patients. (B)Significant differences in liver fibrosis were observed in all patients. (C)various HBV DNA load in HBeAg-positive patient: $39.8 \%$ of patients with>7log DNA load had SLHI, and followed by HBV DNA load decreased, SLHI rate increased. (D)various HBV DNA load in HBeAg-negative patient: $37.7 \%$ of patients with<2000IU/ml DNA load had SLHI, and followed by HBV DNA load increased, SLHI rate increased.

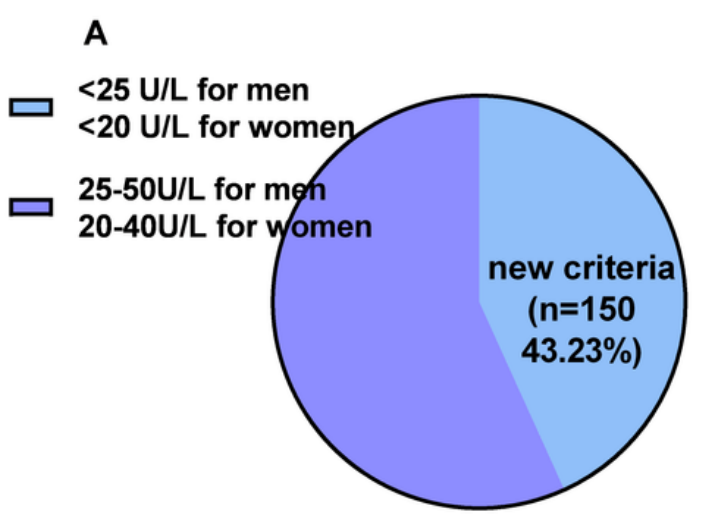

Total $=\mathbf{3 4 7}$

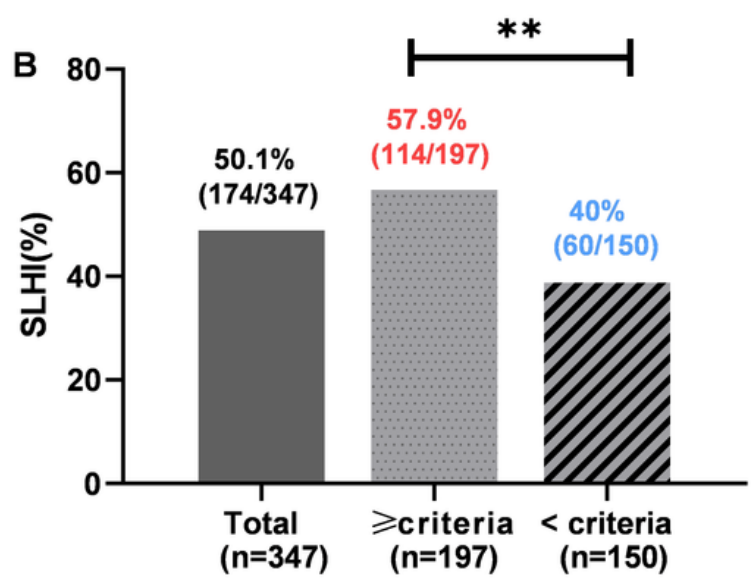

HBeAg-positive patients $(n=200)$
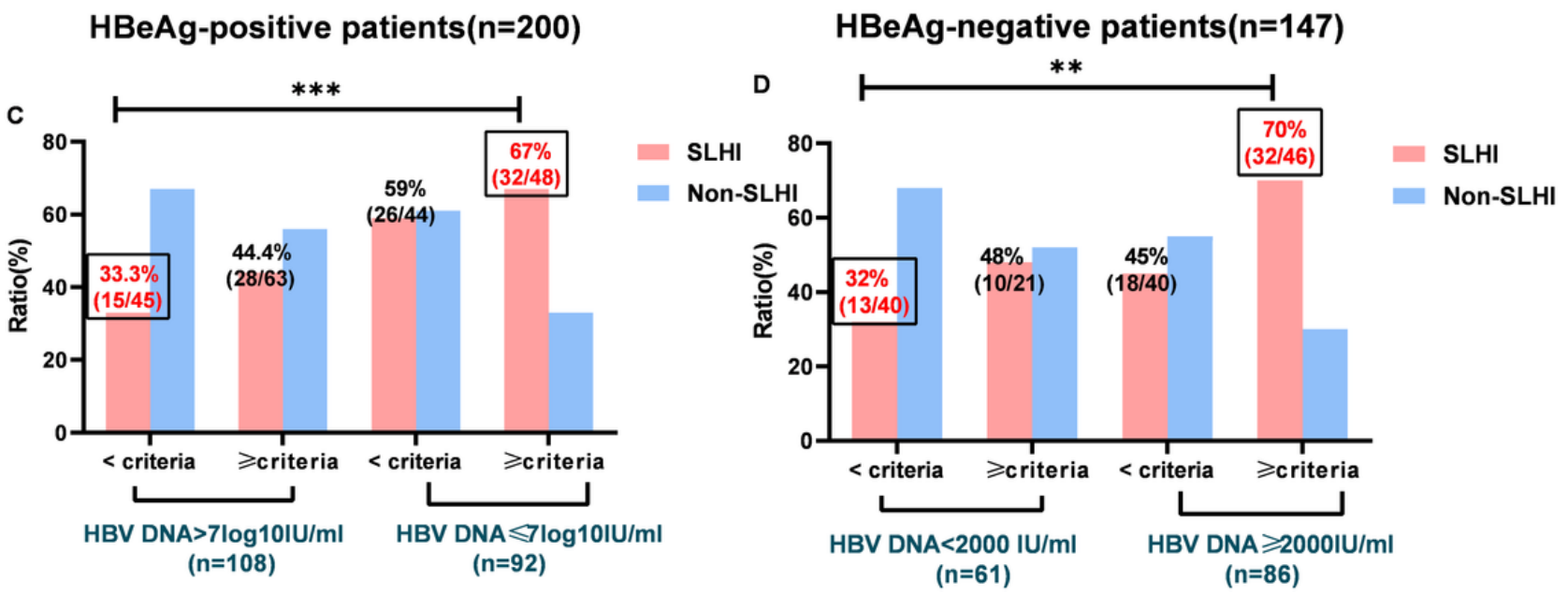

Figure 3

Comparison of proportion of SLHI among patients with normal ALT. (A) Among totally patients with a normal serum ALT,only 43.23\% of them within our cut-off value reference ranges of ALT level. (B)Significant differences in SLHI were observed in patients within our criteria and exceeding our criteria of ALT level. (C)In HBeAg-positive patient: $67 \%$ of patients with $\leqq 7 \mathrm{log}$ IU/ml DNA loads and exceeding our criteria of ALT level had high SLHI. (D)In HBeAg-negative patient: $70 \%$ of patients with>2000IU/ml DNA loads and exceeding our criteria of ALT level had high SLHI. 

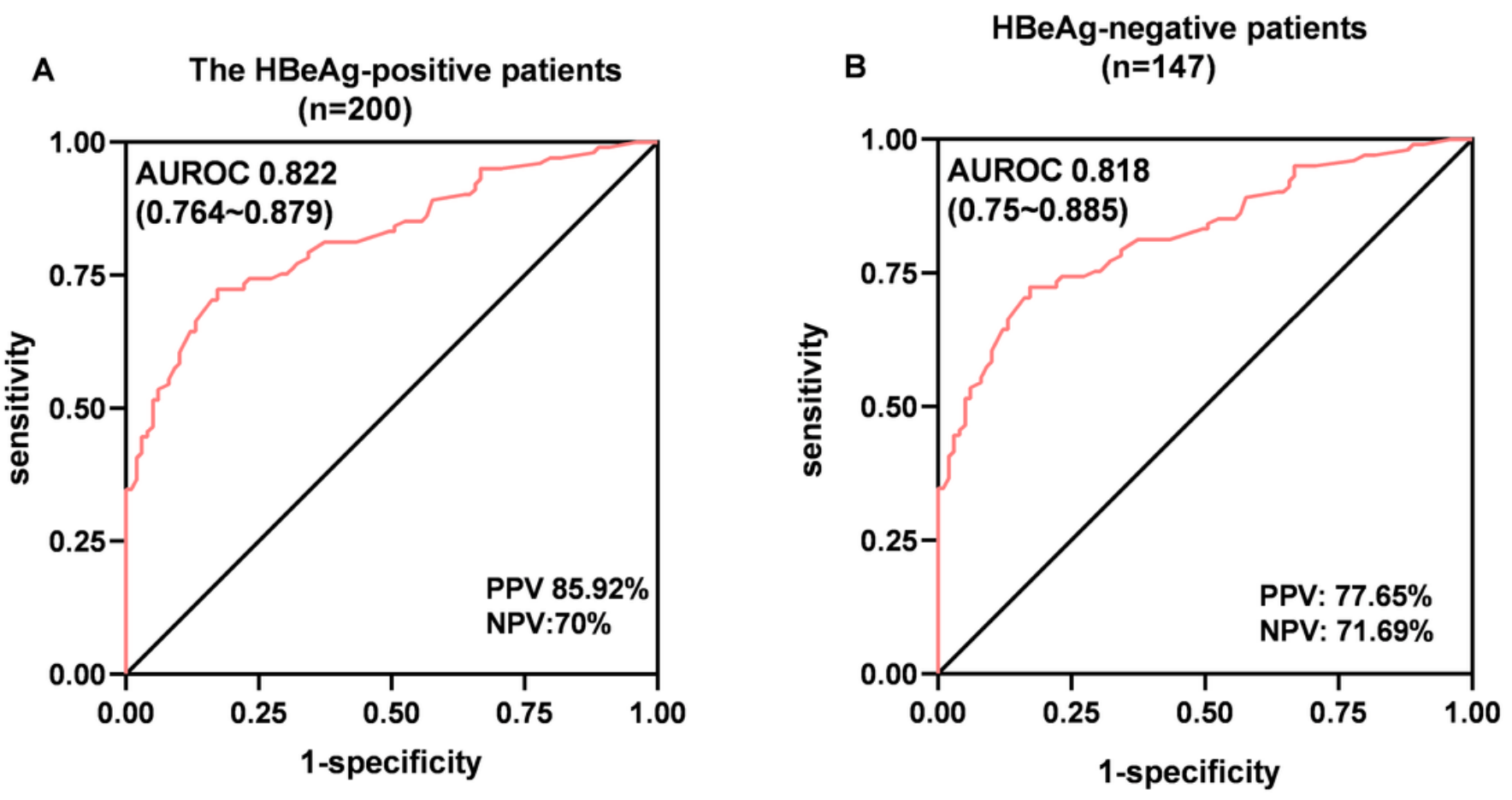

Figure 4

Analysis of AUROC for combination indexes as indicators for SLHI. (A)In HBeAg-positive patients: the AUROC was 0.822 (P<0.001);(B)) In HBeAgnegative patients: the AUROC was $0.818(\mathrm{P}<0.001)$. AUROC, area under the receiving operator characteristic curve.

\section{Supplementary Files}

This is a list of supplementary files associated with this preprint. Click to download.

- supplymentary123.zip 